\title{
A cohort of French pediatric patients with primary immunodeficiencies: are patient preferences regarding replacement immunotherapy fulfilled in real-life conditions?
}

\author{
This article was published in the following Dove Press journal: \\ Patient Preference and Adherence \\ 10 July 2017 \\ Number of times this article has been viewed
}

\author{
Marlène Pasquet ${ }^{1}$ \\ Isabelle Pellier ${ }^{2}$ \\ Nathalie Aladjidi ${ }^{3}$ \\ Anne Auvrignon ${ }^{4}$ \\ Patrick Cherin ${ }^{5}$ \\ Pierre Clerson ${ }^{6}$ \\ Gregoire Jacques Noël \\ Cozon $^{7}$ \\ Roland Jaussaud ${ }^{8}$ \\ Boris Bienvenu9 \\ Cyrille Hoarau ${ }^{10}$
}

'Pediatric Hematology and Oncology Department, University Hospital

Centre of Toulouse, Toulouse,

${ }^{2}$ University Hospital of Angers, Angers, ${ }^{3}$ Paediatric Hematology Unit, CEREVANCE, CIC I40I, Inserm CICP, Hospital Pellegrin,

${ }^{4}$ Trousseau Hospital, Internal Medicine Department, Paris, ${ }^{6}$ Soladis Clinical Studies, Roubaix, ${ }^{7}$ Clinical Immunology, Edouard Herriot Hospital, Lyon, ${ }^{8}$ Internal Medicine and Clinical Immunology Department, University Hospital Centre of Nancy, Nancy, ${ }^{9}$ Internal Medicine Department, University Hospital Centre of Caen, Caen, ${ }^{10}$ Renal Transplantation and Clinical immunology Department, University Hospital Centre of Tours, Tours, France

Correspondence: Marlène Pasquet Pediatric Hematology and Oncology Department, University Hospital Centre of Toulouse, 330 Avenue de la Grande Bretagne, Toulouse 31059, France

Tel +33 534558643

Fax +33 534558612

Email pasquet.m@chu-toulouse.fr
Objective: To assess quality of life and satisfaction regarding immunoglobulin-replacement therapy (IgRT) treatment according to the route (intravenous Ig [IVIg] or subcutaneous Ig [SCIg]) and place of administration (home-based IgRT or hospital-based IgRT).

Subjects and methods: Children 5-15 years old treated for primary immunodeficiency disease (PIDD) with IgRT for $\geq 3$ months were included in a prospective, noninterventional cohort study and followed over 12 months. Quality of life was assessed with the Child Health Questionnaire - parent form (CHQ-PF)-50 questionnaire. Satisfaction with IgRT was measured with a three-dimensional scale (Life Quality Index [LQI] with three components: factor I $\left[\mathrm{F}_{\mathrm{I}}\right]$, treatment interference; $\mathrm{F}_{\mathrm{II}}$, therapy-related problems; $\mathrm{F}_{\mathrm{III}}$, therapy settings).

Results: A total of 44 children ( $9.7 \pm 3.2$ years old) receiving IgRT for a mean of $5.6 \pm 4.5$ years (median 4.1 years) entered the study: 18 (40.9\%) were receiving hospital-based IVIg, two (4.6\%) were receiving home-based IVIg, and 24 (54.6\%) were treated by home-based SCIg. LQI $\mathrm{F}_{\text {III }}$ was higher for home-based SCIg than for hospital-based IVIg $(P=0.0003)$, but there was no difference for LQI $F_{I}$ or LQI $F_{I I}$. LQI $F_{\text {III }}$ significantly improved in five patients who switched from IVIg to SCIg during the follow-up when compared to patients who pursued the same regimen (either IVIg or SCIg). No difference was found on CHQ-PF50 subscales, LQI $\mathrm{F}_{\mathrm{I}}$, or LQI F $\mathrm{II}_{\text {. }}$

Conclusion: Home-based SCIg gave higher satisfaction regarding therapy settings than hospital-based IVIg. No difference was found on other subscales of the LQI or CHQ-PF50 between hospital-based IVIG and home-based SCIG.

Keywords: primary immunodeficiency, pediatric, immunotherapy, immunoglobulins, satisfaction, preference

\section{Introduction}

Primary immunodeficiency disease (PIDD) encompasses more than 340 different disorders of genetic origin characterized by an intrinsic defect in the immune system. ${ }^{1-3}$ Each PIDD is rare, but the global prevalence of PIDD is not negligible, varying from 4.4 to 4.98 per 100,000 inhabitants. ${ }^{4}$ More than $50 \%$ of PIDDs are due to a defect in antibody production. PIDD patients exhibit an increased susceptibility to infections with longer and more frequent infectious episodes, due to a large variety of bacteria, parasites, and fungal agents, and less often viruses. ${ }^{5}$ Antibody-deficiency patients mainly have infections involving the upper and lower respiratory tracts and the gastrointestinal system. ${ }^{6}$ In PIDD children, B-cell defects usually manifest later than 
T-cell defects, because maternal immunoglobulin G ( $\operatorname{IgG})$ levels are still present in the neonatal circulation during the first months of life. In these patients, infections tend to be progressive and unremitting. ${ }^{5}$ Repeated or chronic infection may lead to long-term organ damage.

Ig-replacement therapy (IgRT) aims to restore circulating IgG levels, thus conferring a convenient protection against infections. The mechanisms of action of IVIg are complex, involving modulation of expression and function of $\mathrm{Fc}$ receptors, interference with activation of complement and the cytokine network, and effects on dendritic cells, $\mathrm{T}$ cells, and B cells. ${ }^{7}$ IgRT has been demonstrated to decrease the risk of severe infections, improve quality of life (QoL), prolong survival, ${ }^{8-11}$ and to be cost-effective. ${ }^{12}$ With early diagnosis and adequate treatment, the long-term prognosis can be excellent. ${ }^{13}$ The optimal dose for replacement therapy (RT) in PIDD is still not known; ${ }^{14,15}$ however, it is clear that higher IgG-trough levels decrease hospitalizations due to bacterial infection ${ }^{16}$ and can decrease the rate of other infections as well. ${ }^{17,18}$ Current guidelines promote the role of $\operatorname{IgRT}$ in the prevention of infection in PIDD patients, including pediatric patients. ${ }^{19}$ Titration of dose is based on serum level, but has to be monitored by clinical response. ${ }^{14,15}$ The posology in children and adolescents (aged $0-18$ years) is not different to that of adults, as the posology for each indication is given by body weight and adjusted to the clinical outcome of the aforementioned conditions. ${ }^{20}$ Trough (predose) blood levels of $\operatorname{IgG}$ can be evaluated more frequently initially, and at least once a year after that, to determine if there has been a change in the pharmacokinetics and resultant blood levels of IgG in a specific individual. Ig-dose adjustments are obviously necessary during childhood related to normal growth, or during pregnancy. ${ }^{19}$

Approximately half of PIDD patients are receiving IgRT, ${ }^{4}$ most often as a lifelong treatment. In France in 2006, the population of patients receiving $\operatorname{IgRT}$ was estimated to be 1,500-1,800 patients. ${ }^{21}$ Half of them might be children or young adults. With these patients, the choice of route and place for IgRT administration is of paramount importance to limit the burden of the treatment.

IgRT was first administered by intravenous Ig (IVIg), then the subcutaneous (SC) route became available. IVIg is most often delivered at hospital, whereas SCIg is used in home-based treatment. IVIg and SCIg share similar efficacy for preventing infections. ${ }^{22-26} \mathrm{SCIg}$ allows more stable serum IgG levels between injections, ${ }^{10,27-29}$ and results in normalized or high serum IgG trough concentrations..$^{21,30-32}$ Local reactions are more frequent with SCIg, whereas general systemic reactions are more often observed with IVIg. ${ }^{33} \mathrm{SCIg}$ RT is easy for children to learn and handle, often obviating the need for an infusion nurse. ${ }^{6,10,31,32}$

Health-related QoL (HRQoL) and satisfaction measurements are important issues, particularly for lifelong preventive treatment. Most studies on patients' QoL and satisfaction with substitutive immunotherapy have mixed cohorts of children and adult patients, ${ }^{34,35}$ and few have reported results of specific analyses on pediatric patients. ${ }^{30-32,36-40}$ These cohorts however included a few children (aged 8-37 years), and most of them were receiving IVIg. As far as we know, we report here the most important cohort of pediatric patients followed up in real-life conditions (SCIg or IVIg, at home or at hospital) with special emphasis on HRQoL and satisfaction regarding IgRT.

\section{Subjects and methods}

The objective of the VISAGES study was to describe a cohort of PIDD children receiving IgRT in real-life conditions and over a 1-year follow-up, with special emphasis on IgRT, QoL, and satisfaction. This was a prospective study conducted in France between March 2011 and March 2014. PIDD patients aged 5-15 years receiving IgRT for at least 3 months prior to enrollment and who planned to pursue IgRT for at least 12 further months were eligible for the study. The noninterventional nature of the research protocol was confirmed by the French ethics committee (Comite de Protection des Personnes Ile de France V). The French medical research data-processing advisory committee (Comité Consultatif sur le Traitement de l'Information en Matière de Recherche dans le Domaine de la Santé) and the French informationtechnology and privacy commission (Commission Nationale de l'Informatique et des Libertés) approved the research protocol and related data collection. Parents or guardians of the enrolled children gave written consent after being fully informed on the aims and constraints of the study.

Patients were recruited by hospital centers that were highly experienced in the management of PIDD (16 centers). Collected data included demographic and biometric data. The type, number, and severity of infectious events within the 12 months preceding enrollment and over the follow-up period were reported. Severe infections were defined as meningitis, pneumonia, sepsis, osteitis, or visceral abscess. History of IgRT was collected. IgG serum concentration was reported when monitored. QoL was assessed by the self-administered Child Health Questionnaire - parental form (CHQ-PF50). ${ }^{41}$ The CHQ-PF50 focuses on the physical and psychosocial functioning and well-being of the child 
and his or her family, and aggregates 15 concepts in total. Higher scores indicate a better HRQoL. The CHQ-PF50 is a widely used and valid generic questionnaire, and may be used for patients 5-15 years old without adaptation. Patients' or parents' satisfaction was assessed by the Life Quality Index (LQI), ${ }^{42}$ a disease-specific self-questionnaire that comprises three independent factors: treatment interference (factor I), therapy-related problems (factor II), and therapy settings (factor III). The LQI consists of 15 statements, each rated on a 7-point Likert response scale. Validated French translations of the CHQ-PF50 and LQI were used. The LQI has the advantage of good responsiveness to change. ${ }^{43}$ Strategies combining generic and disease-specific evaluation of QoL are encouraged. ${ }^{43}$

The annual incidence rates of moderate and severe infections were estimated from Poisson regression models using the natural logarithm of the prospective follow-up duration as offset term. LQI scales and CHQ-PF50 dimensions were compared between patients receiving hospital-based IVIg and those treated with SCIg at home using a mixed model with route and place for administration as fixed factors and study center as random factor. Changes in LQI scores between patients who switched from hospital-based IVIg to homebased SCIg were analyzed by the Mann-Whitney $U$ test. Tests were two-sided, and the statistical significance threshold was set at 0.05 . To deal with the inflation of type 1 error due to multiple comparisons, $P$-values were adjusted by the Bonferroni method when comparing the 14 subscales of the CHQ-PF50. Statistical analysis was conducted with SAS 9.3 software (SAS Institute, Cary, NC, US).

\section{Results}

\section{Status at enrollment}

A total of 46 children entered the study. Two enrolled patients were less than 5 years old, and were promptly withdrawn from the study. Therefore, the analysis involved 44 patients meeting the eligibility criteria. They were mainly recruited in pediatric medicine departments (13 centers for 38 patients), internal medicine departments (two centers for five patients) and/or clinical immunology departments (one center for one patient); 39 of 44 had at least one follow-up visit, and 30 patients had one measure of LQI at inclusion and at least one during follow-up (Figure 1). Characteristics of the 44 analyzed patients are summarized in Table 1. Patients were suffering from IgG-subclass deficiency $(\mathrm{n}=14)$, hypogammaglobulinemia $(\mathrm{n}=8), \mathrm{X}$-linked agammaglobulinemia $(n=7)$, agammaglobulinemia $(n=2)$, common variable immunodeficiency $(n=2)$, or other miscellaneous

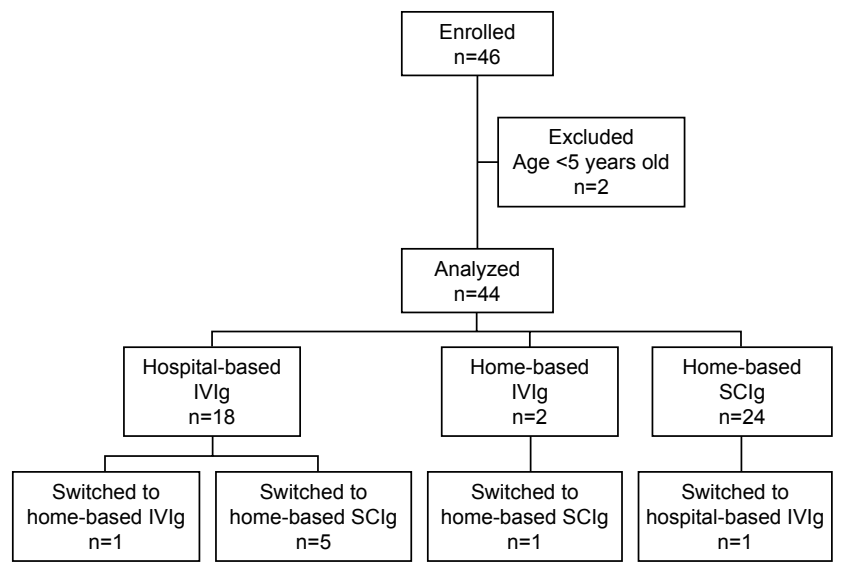

Figure I Study flow diagram.

Abbreviations: IVlg, intravenous lg; $\mathrm{SClg}$, subcutaneous lg.

disorders $(n=11)$. Eleven patients $(25 \%)$ had concomitant asthma. IgRT was ongoing for 5.6 \pm 4.5 years at entry in the study. Since IgRT initiation, 22 patients $(50 \%)$ had switched from IVIg to SCIg, and five patients (11.4\%) had switched from SCIg to IVIg. Past switches from IVIg to SCIg had been largely driven by patient request and physician willingness to preserve patient activity. Tolerability concerns had been the reason for switching from SCIg to IVIg in two of five patients.

\section{Clinical and biological follow-up}

Three patients suffered a total of five infections during the 12-month follow-up period (two SCIg and one IVIg). Three of five infectious episodes were pneumonias. One patient with humoral deficiency in a context of anhidrotic ectodermal dysplasia treated with IVIg had three severe infections. During follow-up, lowest serum IgG levels were $9.89 \mathrm{~g} / \mathrm{L}$, $10.1 \mathrm{~g} / \mathrm{L}$, and $14.9 \mathrm{~g} / \mathrm{L}$ for each of these three patients. The incidence rate of severe infections was 0.15 [0.04-0.6] patient-year. In addition, 16 patients suffered a total of 54 moderate infections ( 21 bronchitis in six children and nine otitis in three). Among the 39 patients analyzed for follow-up, $33(84.6 \%)$ had at least one dosage of serum IgG. Only one patient had one dosage of $\mathrm{IgG}<5 \mathrm{~g} / \mathrm{L}$ during follow-up.

\section{Ig-replacement therapy}

At inclusion in the study, 18 (40.9\%) patients were receiving IVIg at hospital, two (4.6\%) were receiving IVIg at home, and $24(54.6 \%)$ were treated by SCIg at home. Patients treated by IVIg were receiving $527 \pm 233 \mathrm{mg}$ around once a month; patients treated by SCIg were receiving $113 \pm 43 \mathrm{mg}$ $4.2 \pm 0.8$ times per month. Globally, the monthly dose of IgG was $632 \pm 221 \mathrm{mg} / \mathrm{kg}$ for IVIg and $466 \pm 177 \mathrm{mg} / \mathrm{kg}$ for SCIg 
Table I Population characteristics

\begin{tabular}{|c|c|c|c|c|}
\hline & $\begin{array}{l}\text { Population, } \\
\mathrm{n}=44\end{array}$ & $\begin{array}{l}\text { Hospital-based } \\
\operatorname{IgRT}, \mathrm{n}=18\end{array}$ & $\begin{array}{l}\text { Home-based } \\
\operatorname{IgRT}, \mathrm{n}=\mathbf{2 6}\end{array}$ & $P$-value \\
\hline Age (years) & $9.7 \pm 3.2$ & $9 \pm 3.3$ & $10.2 \pm 3$ & 0.23 \\
\hline Males & $25(56.8 \%)$ & $8(44.4 \%)$ & 17 (65.4\%) & 0.17 \\
\hline Age at PIDD diagnosis (years) & $3.7 \pm 2.7$ & $4.2 \pm 2.6$ & $3.4 \pm 2.8$ & 0.38 \\
\hline Time from PIDD diagnosis (years) & $6 \pm 4.2$ & $4.8 \pm 4$ & $6.8 \pm 4.3$ & 0.14 \\
\hline Age at start of IgRT (years) & $4.2 \pm 3$ & $4.7 \pm 2.8$ & $3.8 \pm 3.2$ & 0.3 \\
\hline Duration of $\operatorname{lgRT}$ (years) & $5.6 \pm 4.5$ & $4.3 \pm 4.2$ & $6.5 \pm 4.5$ & 0.12 \\
\hline \multicolumn{5}{|l|}{ to inclusion in the study } \\
\hline \multicolumn{5}{|l|}{ IgRT setting during 12 months before inclusion } \\
\hline Hospital-based & $17(38.6 \%)$ & 17 (94.4\%) & 0 & $<0.000$ I \\
\hline Home-based & $16(36.4 \%)$ & 0 & $16(61.5 \%)$ & \\
\hline Hospital then home-based & 7 (I5.9\%) & 0 & $7(26.9 \%)$ & \\
\hline Home then hospital-based & I (2.7\%) & 0 & $3(11.5 \%)$ & \\
\hline Hospital- and home-based, alternating & $3(6.8 \%)$ & $\mathrm{I}(5.6 \%)$ & 0 & \\
\hline \multicolumn{5}{|l|}{ IgRT regimen during I 2 months before inclusion } \\
\hline - IVIg exclusively & 19 (43.2\%) & 17 (94.4\%) & $2(7.7 \%)$ & $<0.000$ I \\
\hline - SClg exclusively & $15(34.1 \%)$ & 0 & $15(57.7 \%)$ & \\
\hline - IVlg and SClg, alternating & $10(22.7 \%)$ & I (5.6\%) & $9(34.6 \%)$ & \\
\hline \multicolumn{5}{|l|}{$\operatorname{IgRT}$ regimen at inclusion } \\
\hline - Hospital-based IVlg & 18 (40.9\%) & & & \\
\hline - Home-based IVlg & $2(4.6 \%)$ & & & \\
\hline - Home-based SClg & $24(54.6 \%)$ & & & \\
\hline Trough serum IgG level $(\mathrm{g} / \mathrm{L})$ & $9.1 \pm 2.4$ & $8.7 \pm 2.5$ & $9.3 \pm 2.3$ & 0.44 \\
\hline $\begin{array}{l}\text { At least one severe infection within } 12 \text { months } \\
\text { before inclusion }\end{array}$ & $3(6.8 \%)$ & $2(11.1 \%)$ & $4(3.9 \%)$ & 0.56 \\
\hline
\end{tabular}

Note: Results expressed as mean \pm standard deviation and $n$ (\%).

Abbreviations: IgRT, immunoglobulin-replacement therapy; PIDD, primary immunodeficiency disease; IVlg, intravenous Ig; SClg, subcutaneous Ig.

( $P=0.02$ ). Trough-IgG levels ranged from 3.2 to $14.9 \mathrm{~g} / \mathrm{L}$ (mean $9.1 \pm 2.4 \mathrm{~g} / \mathrm{L})$. Three patients had suffered at least one severe infection within the 12 months before inclusion in the study.

Patients were followed up for 359 \pm 76 days (range 90-454 days). Five patients switched from hospital-based IVIg to home-based SCIg, one patient switched from home-based IVIg to home-based SCIg, one patient replaced home-based SCIg with hospital-based IVIg, and one patient switched from hospital-based IVIg to home-based IVIg. Therefore, six patients replaced hospital-based with home-based IgRT. In five of six patients, switches were made at the patient's request. According to the physician, good understanding of advantages and constraints of home-based treatment by the patient was a prerequisite for switching from hospital to home. At the end of the follow-up, 13 patients were receiving hospital-based IVIg, two patients were receiving IVIg at home, and 29 patients were being treated by SCIg at home.

\section{Satisfaction and quality of life}

At inclusion, LQI scales, namely factors I (treatment interference), II (therapy-related problems), and III (therapy setting), were documented by 12 patients receiving hospital-based
IVIg and 17 patients receiving SCIg at home. Results are provided in Table 2. Whereas no significant differences were found on factors I and II, factor III was significantly higher in patients with home-based SCIg, suggesting less disruption in daily life. Since only one patient documented with the LQI was receiving IVIg at home, there was no possible comparison with hospital-based IVIg or home-based SCIg. The CHQ-PF50 was completed by 38 patients. Some subscales of the CHQ-PF50 were altered, although the differences did not reach statistical significance, in PIDD children when compared to healthy children (Figure 2): physical functioning in IVIg patients, bodily pain, general health, and parental impact - time. QoL was globally similar in patients

Table 2 Life Quality Index scale at inclusion

\begin{tabular}{lll}
\hline & $\begin{array}{l}\text { Hospital-based } \\
\text { IVIg, } \mathbf{n = I 2}\end{array}$ & $\begin{array}{l}\text { Home-based } \\
\mathbf{S C l g}, \mathbf{n}=\mathbf{I 7}\end{array}$ \\
\hline Factor I (treatment interference) & $78.6 \pm 12.5$ & $80.5 \pm 13.3$ \\
Factor II (therapy-related problems) & $81.9 \pm 11$ & $80 \pm 14$ \\
Factor III (therapy setting) & $82.1 \pm 12.2$ & $96.4 \pm 6.2^{* *}$ \\
\hline
\end{tabular}

Notes: $* * P=0.0003$. Mixed model, with route and place for administration as fixed factors and study center as random factor. Data are presented as mean \pm standard deviation.

Abbreviations: IVlg, intravenous Ig; $\mathrm{SClg}$, subcutaneous lg. 


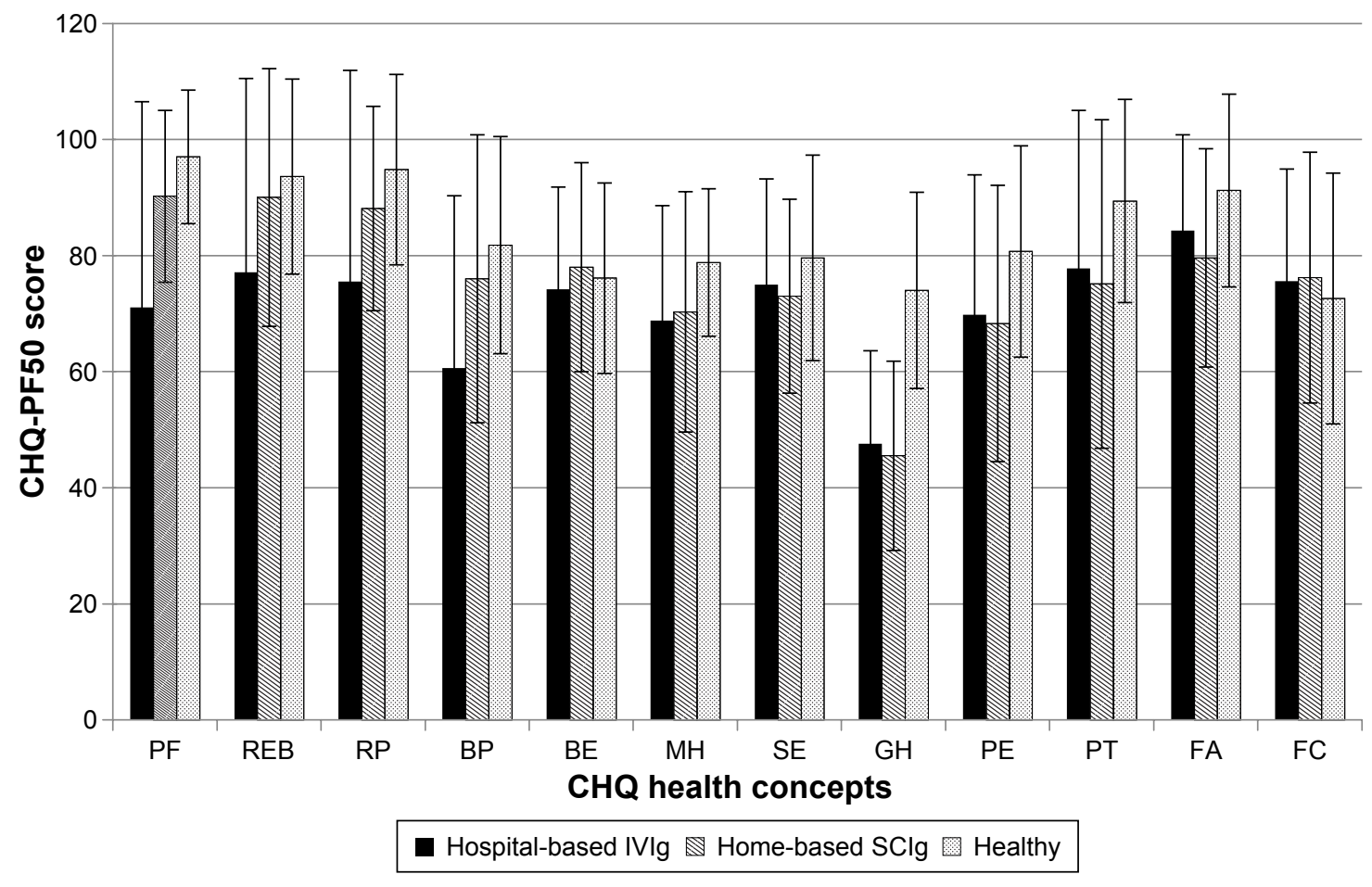

Figure 2 CHQ-PF50 in PIDD children by route of infusion $(n=38)$.

Notes: Not significant for any comparison between route of IgRT in PIDD patients or any comparison between PIDD and healthy patients. Norms of healthy US Caucasian children taken from HealthActCHQ Inc. Child Health Questionnaire Scoring and Interpretation Manual. 2008 HealthActCHQ Inc., Cambridge MA USA. [provided as part of a paid license only] Reproduced with permission from HealthActCHQ for purposes of data presentation and analysis for this study only. Data may not be reproduced with express written permission from HealthActCHQ. ${ }^{41}$

Abbreviations: CHQ-PF50, Child Health Questionnaire - parent form; PIDD, primary immunodeficiency disease; PF, physical functioning; REB, role/social - emotional/ behavioral; RP, role/social - physical; BP, bodily pain (discomfort); BE, behavior; MH, mental health; SE, self-esteem; GH, general health; PE, parental impact - emotional; PT, parental impact - time; FA, family activity; FC, family cohesion; IVlg, intravenous Ig; SClg, subcutaneous Ig; IgRT, immunoglobulin replacement therapy.

receiving hospital-based IVIg and patients on home-based SCIg (Table 3). There was no improvement in any subscale of the CHQ-PF50 in patients who switched from IVIg to SCIg when compared to patients who pursued the same regimen (either IVIg or SCIg) (Table 4). By contrast, LQI factor III (therapy setting) significantly improved with the switch from hospital-based IVIg to home-based SCIg $(P=0.04)$, whereas LQI factors I and II did not vary (Table 5).

Table 3 CHQ-PF50 at inclusion $(n=38)$

\begin{tabular}{|c|c|c|c|}
\hline & $\begin{array}{l}\text { Hospital-based IVIg, } \\
\mathrm{n}=17\end{array}$ & $\begin{array}{l}\text { Home-based SClg, } \\
n=2 \text { I }\end{array}$ & $\begin{array}{l}\text { Overall, } \\
n=38\end{array}$ \\
\hline Global health & $67.7 \pm 14.7$ & $68.3 \pm 20.6$ & $67.5 \pm 18.7$ \\
\hline Physical functioning & $7 I .1 \pm 35.4$ & $90.2 \pm 14.8$ & $81.7 \pm 27$ \\
\hline Role/social limitations - emotional/behavioral & $77.1 \pm 33.4$ & $90 \pm 22.2$ & $84.6 \pm 27.6$ \\
\hline Role/social limitations - physical & $75.5 \pm 36.4$ & $88.1 \pm 17.6$ & $83.3 \pm 27.5$ \\
\hline Bodily pain - discomfort & $60.6 \pm 29.7$ & $76 \pm 24.8$ & $70 \pm 27.6$ \\
\hline Behavior & $74.2 \pm 17.6$ & $78 \pm 18$ & $76.4 \pm 17.4$ \\
\hline Global behavior & $69.4 \pm 21.8$ & $71.7 \pm 23$ & $71.1 \pm 22.2$ \\
\hline Mental health & $68.8 \pm 19.8$ & $70.3 \pm 20.7$ & $69.5 \pm 19.9$ \\
\hline Self-esteem & $75 \pm 18.2$ & $73 \pm 16.7$ & $73.5 \pm 17$ \\
\hline General health perception & $47.6 \pm 16$ & $45.5 \pm 16.3$ & $45.8 \pm 15.8$ \\
\hline Parental impact - emotional & $69.8 \pm 24.1$ & $68.3 \pm 23.8$ & $68.2 \pm 23.7$ \\
\hline Parental impact - time & $77.8 \pm 27.2$ & $75.1 \pm 28.3$ & $75.8 \pm 27$ \\
\hline Family activities & $84.3 \pm 16.5$ & $79.6 \pm 18.8$ & $80.2 \pm 18.7$ \\
\hline Family cohesion & $75.6 \pm 19.3$ & $76.2 \pm 21.6$ & $75.1 \pm 20.1$ \\
\hline
\end{tabular}

Notes: No statistically significant difference for all comparisons after Bonferroni correction for multiple comparisons. Data are presented as mean \pm standard deviation. Abbreviations: CHQ-PF50, Child Health Questionnaire - parent form; IVlg, intravenous lg; SClg, subcutaneous Ig. 
Table 4 Evolution of CHQ-PF50 during follow-up

\begin{tabular}{|c|c|c|}
\hline & $\begin{array}{l}\text { Did not } \\
\text { switch, } n=32\end{array}$ & $\begin{array}{l}\text { Switched from } \\
\text { IVIg to SCIg, n=6 }\end{array}$ \\
\hline Global health & $1.5 \pm 19.9$ & $-17 \pm 15.7$ \\
\hline Physical functioning & $-0.7 \pm 12.5$ & $-7.8 \pm 15.5$ \\
\hline $\begin{array}{l}\text { Role/social limitations - } \\
\text { emotional/behavioral }\end{array}$ & $-3.4 \pm 29.1$ & $2.2 \pm 46.1$ \\
\hline $\begin{array}{l}\text { Role/social limitations - } \\
\text { physical }\end{array}$ & $2.8 \pm 26.8$ & $-13.3 \pm 29.8$ \\
\hline Bodily pain - discomfort & $4.4 \pm 25.2$ & $14 \pm 11.4$ \\
\hline Behavior & $-1.3 \pm|4|$. & $-1.3 \pm 6.2$ \\
\hline Global behavior & $9.6 \pm 19$ & $2 \pm 14.4$ \\
\hline Mental health & $2.2 \pm 13.1$ & $4 \pm 14.3$ \\
\hline Self-esteem & $1.3 \pm 10.9$ & $-1.7 \pm 15.8$ \\
\hline General health perception & $6.5 \pm 12.4$ & $-4.1 \pm 18.5$ \\
\hline Parental impact - emotional & $5.8 \pm 16.6$ & $8.3 \pm 17.7$ \\
\hline Parental impact - time & $1.9 \pm 25.7$ & $-2.2 \pm 9.3$ \\
\hline Family activities & $5.6 \pm 17.2$ & $7.8 \pm 16.1$ \\
\hline Family cohesion & $2.9 \pm 17.9$ & $0 \pm 0$ \\
\hline
\end{tabular}

Notes: No statistically significant difference for any comparison. Data are presented as mean \pm standard deviation.

Abbreviations: CHQ-PF50, Child Health Questionnaire - parent form; IVIg, intravenous lg; $\mathrm{SClg}$, subcutaneous lg.

\section{Patient preference}

Six of 18 patients treated at hospital expressed willingness to be treated at home instead at enrollment in the study. Five of six switched to home-based IgRT during follow-up. On the other hand, two patients treated at home preferred to be treated at hospital instead. Place of administration did not change over the follow-up. One patient expressed a preference for home-based treatment at the end of study, and the other patient had no opinion. These results suggest that physicians pay attention to their patients' wishes.

\section{Discussion}

We report here cross-sectional and longitudinal data of 44 children 5-15 years old with PIDD who were recruited in 16 French pediatric medicine and internal medicine departments.

\section{PIDD impacts physical dimensions of QoL and family activities}

Data on QoL of PIDD children are scarce. We found few studies in PIDD children that had used the CHQ-PF50 for evaluation of QoL..$^{24,39,44-46}$ In comparison with healthy children, our patients rated lower for physical functioning (IVIg patients), bodily pain, general health, and parental impact - time, although the differences did not reach significance. Similar results have been reported previously. ${ }^{37-40,44}$ We found no difference on the behavioral subscale, as previously highlighted by Titman et al. ${ }^{40}$

Gardulf et $\mathrm{al}^{22}$ reported HRQoL and satisfaction in 15 Swedish children less than 14 years old switching from hospital-based IVIg to home-based SCIg. At baseline (ie, before the switch), their patients exhibited a lower level of global health and general health perception, but higher scores for physical functioning, role - physical, and bodily discomfort than patients treated with hospital-based IVIg in the VISAGES cohort. Family activities and parental emotions were more impaired and parental impact on time was greater in Gardulf et al's patients. Zebracki et al stated that PIDD children receiving IV IgRT had a level of QoL similar to those suffering from juvenile inflammatory arthritis (JIA), but that they scored lower than the JIA group with respect to perception of general health and limitations

Table 5 Evolution of Life Quality Index scores during follow-up

\begin{tabular}{lll}
\hline & $\begin{array}{l}\text { Did not switch, } \\
\mathbf{n = 2 4}\end{array}$ & $\begin{array}{l}\text { Switched from IVIg } \\
\text { to SClg, } \mathbf{n = 5}\end{array}$ \\
\hline $\begin{array}{l}\text { Factor I (treatment interference) } \\
\text { - Inclusion }\end{array}$ & $80.6 \pm 11.7$ & $81 \pm 13.8$ \\
- End of study & $82 \pm 11.4$ & $91.9 \pm 9.5$ \\
- Change during the study & $1.5 \pm 13.7$ & $11 \pm 9.6$ \\
Factor II (therapy-related problems) & & \\
- Inclusion & $81 \pm 13.1$ & $80.7 \pm 11.7$ \\
- End of study & $81.9 \pm 10.2$ & $90 \pm 13.9$ \\
- Change during the study & $1 \pm 10.9$ & $9.3 \pm 7.8$ \\
Factor III (therapy setting) & & \\
- Inclusion & $91.5 \pm 10.3$ & $84.8 \pm 15.6$ \\
- End of study & $88.9 \pm 15.9$ & $95.2 \pm 8.3$ \\
- Change during the study & $-2.6 \pm 8.8$ & $10.5 \pm 8.5$ \\
\hline
\end{tabular}

Notes: $P$-values derived from a mixed model, with switch and baseline as fixed factors and center as random factor. Data are presented as mean \pm standard deviation. Abbreviations: IVIg, intravenous Ig; SClg, subcutaneous lg. 
on parental time and family activities. ${ }^{39}$ Comparing the CHQ-PF50 scores of patients with JIA, we found that PIDD children had lower scores for role - social/emotional/ behavioral, role - physical, mental health, general health perception, and parental impact - time, but differences did not reach significance.

\section{Place and route of IgRT had no impact on generic QoL, but impacted patient satisfaction with lgRT}

QoL was globally similar in patients receiving hospitalbased IVIg and patients with home-based SCIg. There was no difference between hospital-based IVIg and home-based SCIg on LQI factor I (treatment interference) or LQI factor II (therapy-related problems), but QoL related to therapy setting was significantly higher $(P=0.0003)$ in patients receiving home-based SCIg. SCIg has already been reported to increase patient and family satisfaction with IgRT. ${ }^{47}$

\section{Switch from hospital-based IVIg to home- based SClg had no impact on QoL, but improved satisfaction with IgRT}

No difference was found on CHQ-PF50 subscores between patients having switched from hospital-based IVIg to homebased SCIg and those who pursued the same regimen, but comparisons suffered from an evident lack of power. Similar results have recently been reported in a small study involving five patients. ${ }^{46}$ Other authors have reported significant improvements in areas related to the children's social functioning, ${ }^{24,44,45}$ general health, ${ }^{24,36,44,45}$ parents' life situation, ${ }^{24,36,44}$ and family functioning. ${ }^{36,44,45}$ Children had improved social functioning and fewer missed school days. ${ }^{24,44}$ It remains unclear if improvement in QoL is related to change in IgRT route or change in administration setting. $\mathrm{SC}$ administration is closely related to home-based treatment, while IVIg is most often administered at hospital. The review of 25 studies not specifically addressing children noted that though transition from hospital-based IVIg to home-based SCIg therapy improved HRQoL, this improvement seemed to be largely related to home therapy. ${ }^{24}$ Home-based IVIg compared to hospital-based IVIg improves independence and convenience and lessens disruption of activities.

In the VISAGES study, only five patients switched from hospital-based IVIg to home-based SCIg, and lack of power could at least partially explain the absence of improvement, in contrast with other studies. However, even when crude numbers were examined, there was no evident trend toward improvements in some areas of QoL. This could also be due to higher baseline values, especially in areas related to parental impact and family activities, perhaps reflecting specificities of health systems. Differences in methods could also be plausible explanations. In Gardulf et al, ${ }^{44}$ patients were eligible if they accepted to switch from hospital-based IVIg to homebased SCIg, whereas the VISAGES study was conducted in real-life conditions and patients switched mostly at their own request. Some patients had switched before inclusion in the study, and a previous switch may have optimized QoL. Finally, it has been suggested that tools measuring generic QoL may have too low a responsiveness to change.

The LQI evaluated specific QoL in PIDD patients. Whereas at inclusion, no difference was found between hospital-based IVIg and home-based SCIg on factors measuring treatment interference and therapy-related problems, factor III (therapy setting) was significantly higher in patients receiving home-based SCIg. Switch from hospital-based IVIg to home-based SCIg led to a significant improvement in LQI factor III. Significant improvements in LQI scores with switch to home-based treatment have already been reported..$^{8,32,35,44} \mathrm{We}$ found the same results in a population of adult patients, ${ }^{48}$ and we concluded that satisfaction regarding IgRT cannot be confounded with QoL and that generic measures of QoL encompass different underlying concepts than the LQI.

\section{Patient preference}

Patient preference is not univocal. Not all patients prefer SC therapy when given a choice. ${ }^{49}$ For children, some parents may prefer them to receive injections at hospital because of the ease of organization and the quality of care and follow-up, while others would prefer home-based treatment due to the lower impact on parents' work and daily activities. Numerous factors may influence the patient's preference for hospitalbased or home-based treatment, including accessibility to infusion center, ability of the patients or their parents to learn the infusion technique, safety, security, and cleanliness of the home. ${ }^{50}$ Ten of 18 patients who at entry were treated at hospital and all but two patients who were treated at home confirmed that the actual place of administration was their preference. In a survey conducted by an association of PIDD patients in 2006 following the availability of SCIg and the introduction of home-based treatment, the patients declared they were satisfied by the route and place of administration if they were the results of their own choices. ${ }^{51}$ In other studies, families have reported they prefer the shorter, more frequent infusions at home to the more disruptive and lengthy visits 
to a hospital. ${ }^{32,52}$ Moreover, parents and children have highlighted greater feelings of independence with home-based therapy. ${ }^{31}$ Generally, after having been switched from IVIg to $\mathrm{SCIg}$, children and their parents reported that they preferred home-based SCIg. ${ }^{44,24}$ Choosing the right patient, providing proper support, and managing expectations are crucial to ensuring that patients with PIDD achieve the maximum benefit from therapy.

\section{Limitations}

This study has some limitations. Due to its observational nature, visits were not prescheduled. Infectious events were documented retrospectively by the physician at further visits. Residual IgG levels were not monitored on a regular basis. Switches from IVIg to SCIg or from hospital-based to home-based treatment were decided in real-life conditions and were not randomized. Therefore, the group of patients whose modalities of IgRT remained unchanged cannot be considered a control group. Despite only a small series of pediatric PIDD patients receiving IgRT having been published before now and the fact that we report one of the most important cohorts, our population consisted of only 44 patients. ${ }^{30-32,36-40}$ Further studies involving a larger number of patients are warranted.

\section{Conclusion}

This study confirmed that PIDD impairs children's QoL. Home-based SCIg compared to IVIg was associated with higher satisfaction regarding IgRT, but patient preference was not univocal. Therefore, hospital-based IgRT and homebased IgRT must be considered as options to be proposed to the patient. IgRT is a long-term therapy, and patients' wishes may vary over time. The high level of satisfaction expressed by the patients suggests that physicians pay attention to their patients' preferences.

\section{Acknowledgments}

The authors thank all participants who included pediatric patients in the VISAGES study: M Abdelhadi (MD), Provins, France; N Aladjidi (MD), Paris, France; A Auvrignon (MD), Paris, France; B Bienvenu (MD, PhD), Caen, France; G Couillaut (MD), Dijon, France; I Hau-Rainsart (MD), Créteil, France; E Jezioksi (MD), Montpellier, France; G Kanny (MD), Nancy, France; F Mazinfue (MD), Lille, France; J Mulliez-Petitpas (MD), Poitiers, France; M Munzer (MD), Reims, France; M Ouachée (MD), Paris, France; I Pellier-Landreau (MD), Angers, France; A Salmon (MD), Vandoeuvre-les-Nancy, France.

\section{Disclosure}

The study was sponsored by Octapharma France. The sponsor validated the study design, participated in the interpretation of data, had no role in the writing of the study report, and supported the decision to submit the manuscript for publication. $\mathrm{BB}, \mathrm{GJC}, \mathrm{CH}, \mathrm{PC}$, and RJ are part of the scientific committee for the VISAGES study and earned fees from Octapharma. IP, NA, AA, PC, GJC, RJ, BB, and $\mathrm{CH}$ were investigators for the VISAGES study. BB, PC, GJC, $\mathrm{CH}$, and RJ take part in several scientific boards and also in several studies led by Octapharma. PC works as an independent statistician and earned fees from Octapharma to conduct the statistical analysis and draft the manuscript. The authors report no other conflicts of interest in this work.

\section{References}

1. Notarangelo L, Casanova JL, Conley ME, et al. Primary immunodeficiency diseases: an update from the International Union of Immunological Societies Primary Immunodeficiency Diseases Classification Committee Meeting in Budapest, 2005. J Allergy Clin Immunol. 2006;117(4):883-896.

2. Al-Herz W, Bousfiha A, Casanova JL, et al. Primary immunodeficiency diseases; an update on the classification from the international union of immunological societies expert committee for primary immunodeficiency. Front Immunol. 2014;5:162.

3. Picard C, Al-Herz W, Bousfiha A, et al. Primary immunodeficiency diseases: an update on the classification from the International Union of Immunological Societies Expert Committee for Primary Immunodeficiency 2015. J Clin Immunol. 2015;35(8):696-726.

4. Gathmann B, Binder N, Ehl S, Kindle G. The European Internet-based patient and research database for primary immunodeficiencies: update 2011. Clin Exp Immunol. 2011;167(3):479-491. [retracted].

5. Champi C. Primary immunodeficiency disorders in children: prompt diagnosis can lead to lifesaving treatment. J Pediatr Health Care. 2002; 16(1):16-21.

6. Gardulf A. Immunoglobulin treatment for primary antibody deficiencies: advantages of the subcutaneous route. BioDrugs. 2007;21(2): 105-116.

7. Negi VS, Elluru S, Sibéril S, et al. Intravenous immunoglobulin: an update on the clinical use and mechanisms of action. J Clin Immunol. 2007; 27(3):233-245.

8. Nicolay U, Kiessling P, Berger M, et al. Health-related quality of life and treatment satisfaction in North American patients with primary immunedeficiency [sic] diseases receiving subcutaneous IgG selfinfusions at home. J Clin Immunol. 2006;26(1):65-72.

9. Gardulf A, Nicolay U. Replacement IgG therapy and self-therapy at home improve the health-related quality of life in patients with primary antibody deficiencies. Curr Opin Allergy Clin Immunol. 2006;6(6): 434-442.

10. Misbah S, Sturzenegger MH, Borte M, et al. Subcutaneous immunoglobulin: opportunities and outlook. Clin Exp Immunol. 2009; 158 Suppl 1:51-59.

11. Wood P. Human normal immunoglobulin in the treatment of primary immunodeficiency diseases. Ther Clin Risk Manag. 2012;8:157-167.

12. Beauté J, Levy P, Millet V, et al. Economic evaluation of immunoglobulin replacement in patients with primary antibody deficiencies. Clin Exp Immunol. 2009;160(2):240-245.

13. Wood P, Stanworth S, Burton J, et al. Recognition, clinical diagnosis and management of patients with primary antibody deficiencies: a systematic review. Clin Exp Immunol. 2007;149(3):410-423. 
14. Kobrynski L. Subcutaneous immunoglobulin therapy: a new option for patients with primary immunodeficiency diseases. Biologics. 2012;6: 277-287.

15. Kerr J, Quinti I, Eibl M, et al. Is dosing of therapeutic immunoglobulins optimal? A review of a three-decade long debate in Europe. Front Immunol. 2014;5:629.

16. Quartier P, Debré M, De Blic J, et al. Early and prolonged intravenous immunoglobulin replacement therapy in childhood agammaglobulinemia: a retrospective survey of 31 patients. J Pediatr. 1999;134(5):589-596.

17. Roifman CM, Schroeder H, Berger M, et al. Comparison of the efficacy of IGIV-C, 10\% (caprylate/chromatography) and IGIV-SD, 10\% as replacement therapy in primary immune deficiency: a randomized double-blind trial. Int Immunopharmacol. 2003;3(9):1325-1333.

18. Sriaroon P, Ballow M. Immunoglobulin replacement therapy for primary immunodeficiency. Immunol Allergy Clin North Am. 2015;35(4): 713-730.

19. Aguilar C, Malphettes M, Donadieu J, et al. Prevention of infections during primary immunodeficiency. Clin Infect Dis. 2014;59(10): $1462-1470$.

20. European Medicines Agency. Guideline on core SmPC for human normal immunoglobulin for subcutaneous and intramuscular administration. 2015. Available from: http://www.ema.europa.eu/docs/en_GB/ document_library/Scientific_guideline/2015/03/WC500184870.pdf. Accessed May 1, 2017.

21. Association IRIS. Enquête sur le traitement substitutif en immunoglobulines auprès de patients atteints de deficits immunitaires primitifs. 2006. Available from: http://docplayer.fr/12693266-Enquete-surle-traitement-substitutif-en-immunoglobulines-aupres-de-patientsatteints-de-deficits-immunitaires-primitifs.html. Accessed May 1, 2017.

22. Gardulf A, Nicolay U, Asensio O, et al. Rapid subcutaneous IgG replacement therapy is effective and safe in children and adults with primary immunodeficiencies: a prospective, multi-national study. J Clin Immunol. 2006;26(2):177-185.

23. Chapel HM, Spickett GP, Ericson D, Engl W, Eibl MM, Bjorkander J. The comparison of the efficacy and safety of intravenous versus subcutaneous immunoglobulin replacement therapy. J Clin Immunol. 2000;20(2):94-100.

24. Fasth A, Nyström J. Safety and efficacy of subcutaneous human immunoglobulin in children with primary immunodeficiency. Acta Paediatr. 2007;96(10):1474-1478.

25. Wasserman RL. Hizentra for the treatment of primary immunodeficiency. Expert Rev Clin Immunol. 2014;10(10):1293-1307.

26. Lingman-Framme J, Fasth A. Subcutaneous immunoglobulin for primary and secondary immunodeficiencies: an evidence-based review. Drugs. 2013;73(12):1307-1319.

27. Gardulf A, Hammarström L, Smith CI. Home treatment of hypogammaglobulinaemia with subcutaneous gammaglobulin by rapid infusion Lancet. 1991;338(8760):162-166.

28. Waniewski J, Gardulf A, Hammarström L. Bioavailability of $\gamma$-globulin after subcutaneous infusions in patients with common variable immunodeficiency. J Clin Immunol. 1994;14(2):90-97.

29. Berger M. Subcutaneous immunoglobulin replacement in primary immunodeficiencies. Clin Immunol. 2004;112(1):1-7.

30. Thomas MJ, Brennan VM, Chapel HH. Rapid subcutaneous immunoglobulin infusions in children. Lancet. 1993;342(8884): 1432-1433.

31. Abrahamsen TG, Sandersen H, Bustnes A. Home therapy with subcutaneous immunoglobulin infusions in children with congenital immunodeficiencies. Pediatrics. 1996;98(6 Pt 1):1127-1131.

32. Gaspar J, Gerritsen B, Jones A. Immunoglobulin replacement treatment by rapid subcutaneous infusion. Arch Dis Child. 1998;79(1): 48-51.

33. Cherin P, Marie I, Michallet M, et al. Management of adverse events in the treatment of patients with immunoglobulin therapy: a review of evidence. Autoimmun Rev. 2016;15(1):71-81.
34. Ochs HD, Gupta S, Kiessling P, Nicolay U, Berger M. Safety and efficacy of self-administered subcutaneous immunoglobulin in patients with primary immunodeficiency diseases. J Clin Immunol. 2006; 26(3):265-273.

35. Daly PB, Evans JH, Kobayashi RH, et al. Home-based immunoglobulin infusion therapy: quality of life and patient health perceptions. Ann Allergy. 1991;67(5):504-510.

36. Hoffmann F, Grimbacher B, Thiel J, Peter HH, Belohradsky BH. Homebased subcutaneous immunoglobulin $\mathrm{G}$ replacement therapy under real-life conditions in children and adults with antibody deficiency. Eur J Med Res. 2010;15(6):238-245.

37. Kuburovic NB, Pasic S, Susic G, et al. Health-related quality of life, anxiety, and depressive symptoms in children with primary immunodeficiencies. Patient Prefer Adherence. 2014;8:323-330.

38. Soresina A, Nacinovich R, Bomba M, et al. The quality of life of children and adolescents with X-linked agammaglobulinemia. J Clin Immunol. 2009;29(4):501-507.

39. Zebracki K, Palermo TM, Hostoffer R, Duff K, Drotar D. Healthrelated quality of life of children with primary immunodeficiency disease: a comparison study. Ann Allergy Asthma Immunol. 2004;93(6): 557-561.

40. Titman P, Allwood Z, Gilmour C, et al. Quality of life in children with primary antibody deficiency. J Clin Immunol. 2014;34(7):844-852.

41. HealthActCHQ Inc. Child Health Questionnaire Scoring and Interpretation Manual. 2008 HealthActCHQ Inc., Cambridge MA USA.

42. Nicolay U, Haag S, Eichmann F, Herget S, Spruck D, Gardulf A. Measuring treatment satisfaction in patients with primary immunodeficiency diseases receiving lifelong immunoglobulin replacement therapy. Qual Life Res. 2005;14(7):1683-1691.

43. Jiang F, Torgerson TR, Ayars AG. Health-related quality of life in patients with primary immunodeficiency disease. Allergy Asthma Clin Immunol. 2015;11:27.

44. Gardulf A, Nicolay U, Math D, et al. Children and adults with primary antibody deficiencies gain quality of life by subcutaneous IgG selfinfusions at home. J Allergy Clin Immunol. 2004;114(4):936-942.

45. Berger M, Murphy E, Riley P, Bergman GE. Improved quality of life, immunoglobulin $\mathrm{G}$ levels, and infection rates in patients with primary immunodeficiency diseases during self-treatment with subcutaneous immunoglobulin G. South Med J. 2010;103(9):856-863.

46. Vultaggio A, Azzari C, Milito C, et al. Subcutaneous immunoglobulin replacement therapy in patients with primary immunodeficiency in routine clinical practice: the VISPO prospective multicenter study. Clin Drug Investig. 2015;35(3):179-185.

47. Abolhassani H, Sadaghiani MS, Aghamohammadi A, Ochs HD, Rezaei N. Home-based subcutaneous immunoglobulin versus hospital-based intravenous immunoglobulin in treatment of primary antibody deficiencies: systematic review and meta analysis. J Clin Immunol. 2012;32(6): 1180-1192.

48. Bienvenu B, Cozon G, Hoarau C, et al. Does the route of immunoglobin replacement therapy impact quality of life and satisfaction in patients with primary immunodeficiency? Insights from the French cohort "Visages". Orphanet Journal of Rare Diseases. 2016;11(1):83.

49. Skoda-Smith S, Torgerson TR, Ochs HD. Subcutaneous immunoglobulin replacement therapy in the treatment of patients with primary immunodeficiency disease. Ther Clin Risk Manag. 2010;6:1-10.

50. Berger M. Principles of and advances in immunoglobulin replacement therapy for primary immunodeficiency. Immunol Allergy Clin North Am. 2008;28(2):413-437, x.

51. Kittner JM, Grimbacher B, Wulff W, Jäger B, Schmidt RE. Patients' attitude to subcutaneous immunoglobulin substitution as home therapy. $J$ Clin Immunol. 2006;26(4):400-405.

52. Dams ET, van der Meer JW. Subcutaneous immunoglobulin replacement in patients with primary antibody deficiencies. Lancet. 1995; 345(8953):864. 
Patient Preference and Adherence

Dovepress

\section{Publish your work in this journal}

Patient Preference and Adherence is an international, peer-reviewed, open access journal that focuses on the growing importance of patient preference and adherence throughout the therapeutic continuum. Patient satisfaction, acceptability, quality of life, compliance, persistence and their role in developing new therapeutic modalities and compounds to optimize

clinical outcomes for existing disease states are major areas of interest for the journal. This journal has been accepted for indexing on PubMed Central. The manuscript management system is completely online and includes a very quick and fair peer-review system, which is all easy to use. Visit http://www. dovepress.com/testimonials.php to read real quotes from published authors.

Submit your manuscript here: http://www.dovepress.com/patient-preference-and-adherence-journal 